Communications in Physics, Vol. 27, No. 2 (2017), pp. 173-179

DOI:10.15625/0868-3166/27/2/9631

\title{
STRUCTURAL AND OPTICAL PROPERTIES OF $\mathrm{SrTiO}_{3}$ NANO MATERIAL OBTAINED BY SOL-GEL METHOD
}

\author{
DOAN THI THUY PHUONG ${ }^{1, \dagger}$, NGUYEN XUAN HUY ${ }^{2}$, LE THI MAI OANH ${ }^{2,3}$, \\ DO DANH BICH ${ }^{3}$ AND TRIEU THI MINH CHAU ${ }^{1}$ \\ ${ }^{1}$ Faculty of Basic Sciences, University of Transport and Communications, \\ 3 Cau Giay Road, Dong Da District, Hanoi, 100000, Vietnam \\ ${ }^{2}$ Center for Nano Science and Technology, Hanoi University of Education, \\ 136 Xuan Thuy Road, Cau Giay District, Hanoi, 100000, Vietnam \\ ${ }^{3}$ Department of Physics, Hanoi National University of Education, \\ 136 Xuan Thuy Road, Cau Giay District, Hanoi, 100000, Vietnam \\ ${ }^{\dagger}$ E-mail: phuongthuydoan@utc.edu.vn \\ Received 01 April 2017 \\ Accepted for publication 17 July 2017 \\ Published 31 July 2017
}

\begin{abstract}
SrTiO}_{3}$ (STO) nano particles were prepared by sol-gel process in order to optimize the temperature condition suited for obtaining good quality materials for different applications. The thermal treating condition was selected out through XRD, FTIR and Raman analyses of the synthesized powder. The structural and optical properties of the powder were studied carefully with XRD, SEM, FTIR, Raman and UV-Vis measurements. At optimized annealing temperature (from $900{ }^{\circ} \mathrm{C}$ to $1000^{\circ} \mathrm{C}$ ), the synthesized STO nano particles have a good structure. The shape, size and optical band gap of the obtained material are suitable for further applications.
\end{abstract}

Keywords: $\mathrm{ABO}_{3}, \mathrm{SrTiO}_{3}$, sol-gel process, structure analysis.

Classification numbers: 81.07.-b, 73.22.-f, 81.20.Fw.

\section{INTRODUCTION}

Recently the compounds with the perovskite structure, especially $\mathrm{ABO}_{3}(\mathrm{~A}=\mathrm{Sr}, \mathrm{Ba}, \mathrm{Pb}$, $\mathrm{Ca}$ and $\mathrm{B}=\mathrm{Ti}, \mathrm{Zr}$ ), have been widely investigated because of their great application in science and life. $\mathrm{ABO}_{3}$ materials show interesting properties such as luminosity [1], ferroelectricity [2], piezoelectricity [3]. These materials were investigated in application for making capacitors, varistors, photoelectrodes, ferroelectric memory, sensitivity gas sensors, etc., [1-5].

(C)2017 Vietnam Academy of Science and Technology 
Among $\mathrm{ABO}_{3}$ materials, strontium titanate $\mathrm{SrTiO}_{3}$ (STO) has been being investigated mostly, especially after their ferroelectricity was discovered. Due to their relatively high dielectric constant, which gradually increases when being cooled, and their low short wave loss, these materials are applied in high-frequency components, shortwave devices, especially in low temperature conditions [6]. The publications of STO mostly focus on doping or replacing metal ions to the positions of $\mathrm{Sr}$ or $\mathrm{Ti}$ because the distorted cubic structures could cause many new physical phenomena.

Finding technique to synthesize STO or doped STO powder with high quality structure and reduce fabrication time are interested by many researchers. High energy ball milling was used by $\mathrm{S}$ Malo et al. [7] to develop $\mathrm{SrTi}_{1-x} \mathrm{Co}_{x} \mathrm{O}_{3}$ samples with calcination temperature of $1100^{\circ} \mathrm{C}$ in 12 hours. S Rodewald et al. [8] successfully developed $0.2 \%$ mol Fe by solid state reaction after sintering samples at $1480^{\circ} \mathrm{C}$ in 28.5 hours. Silva L.F.D et al. [9] had successfully fabricated $\mathrm{SrTi}_{1-x} \mathrm{Fe}_{x} \mathrm{O}_{3}$ samples by sol-gel process with sintering temperature of $800^{\circ} \mathrm{C}$ in 4 hours. However, the optimization conditions suited for obtaining STO with good structure and optical properties are still needed to be clarified. In this paper, a sol-gel method was developed to synthesize $\mathrm{SrTiO} 3$ crystallites with the spherical like shape. The temperature condition was also optimized to get the STO material with best structure.

\section{EXPERIMENTAL}

In this work, STO materials were prepared by the sol-gel method. Stronti nitrat - $\operatorname{Sr}\left(\mathrm{NO}_{3}\right)_{2}$, Titanium tetra-isoproxide (TTiP) - Ti $\left[\mathrm{OCH}\left(\mathrm{CH}_{3}\right)_{2}\right]_{4}$, Axit citric $-\mathrm{C}_{6} \mathrm{H}_{8} \mathrm{O}_{7} \cdot \mathrm{H}_{2} \mathrm{O}$ and Ethylene glycol - $\mathrm{C}_{2} \mathrm{H}_{6} \mathrm{O}_{2}$ were used as precursors. They were weighed according to their nominal compositions. 7 gram of axit citric was put into $28 \mathrm{ml}$ of water and slowly stirred in 5 minutes (solution A). Then $1.6 \mathrm{ml} \mathrm{TtiP}$ was dropped into solution A and was heating stirred until a crystal appeared. 1.15 gram of stronti nitrat was put into $28 \mathrm{ml}$ of water and stirred in 15 minutes (solution $\mathrm{B}$ ). Then $2 \mathrm{ml}$ of Ethylen glycol was dropped into the mixture of B and A. The final solution was heating stirred until dried. The formed gel was dried in the oven at $150{ }^{\circ} \mathrm{C}$. Then the samples were calcined at different temperatures $\left(600^{\circ} \mathrm{C}, 700^{\circ} \mathrm{C}, 800^{\circ} \mathrm{C}, 900^{\circ} \mathrm{C}\right.$ and $\left.1000^{\circ} \mathrm{C}\right)$ in 4 hours.

Structure properties of sample were performed by the X-ray powder diffraction (XRD) using the Siemens D5005 diffractometer with $\mathrm{Cu}-\mathrm{K}_{\alpha}$ (= $1.54056 \AA$ A $)$ radiation. The field emission scanning electron microscopy (FE-SEM) observation was carried out by using an S-4800, (Hitachi) microscope. Raman scattering spectroscopy was recorded at room temperature in back scattering geometry using Labram HR 800 spectrometer. The absorption spectrometry was performed and measured by using a Jasco $670 \mathrm{UV}$ sspectrometer. The Fourier transform infrared spectroscopy (FTIR) was recorded in transmission mode on a Shimadzu spectrometer.

\section{RESULTS AND DISCUSSION}

The structure of the sample was first investigated by the power X-ray diffraction (XRD). Figure 1 shows the XRD patterns of STO after a 4-hour calcination at different temperatures (from 600 to $1000^{\circ} \mathrm{C}$ ). The diffraction peaks, appeared at angle $2 \theta$ approximately $32.26^{\circ}, 39.76^{\circ}, 46.30^{\circ}$, $57.66^{\circ}$ and $67.73^{\circ}$, identify that the STO crystal has a cubic structure of the space group Pm $3 \mathrm{~m}$ with the lattice constant $a=3.91 \AA$. These results are in a good agreement with the JCPDS card No.35-734. The XRD diagram also showed that after annealing at $600-700^{\circ} \mathrm{C}$ for $4 \mathrm{~h}$, the crystal 
started forming with the appearance of the diffraction peacks for (211) and (200) planes of the cubic perovskite structure. These peaks become narrow and sharp as the annealing temperature increased. The patterns clearly show that all STO samples are in single phase. The best crystallization quality of STO structure would be obtained by annealing at $900^{\circ} \mathrm{C}-1000{ }^{\circ} \mathrm{C}$. These results are consistent with the previous studies [10-12]. The particle size of samples was calculated from XRD pattern by using the Debye - Scherrer formula. The result shows that when the calcination temperature increased, the crystal particle size also increased from $17 \mathrm{~nm}$ to $33 \mathrm{~nm}$.

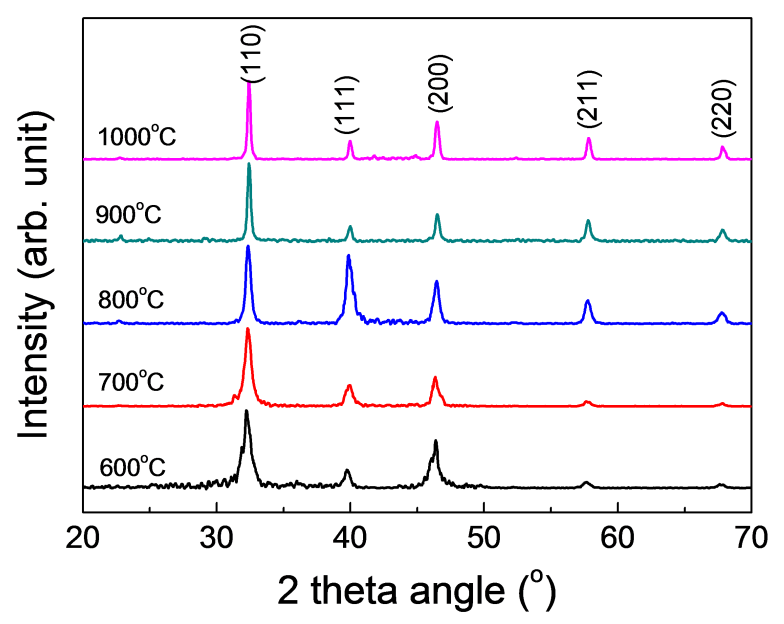

Fig. 1. X-ray diffraction diagrams of STO sample in temperatures $600^{\circ} \mathrm{C}-1000^{\circ} \mathrm{C}$.

The morphology of prepared STO materials was characterized by FE-SEM. Figure 2 presents SEM image of STO samples after being calcinated at different temperatures. Results showed that the particles were in irregular shape based on a spherical morphology. The particle size increased as the annealing temperature increased from $600^{\circ} \mathrm{C}$ to $1000^{\circ} \mathrm{C}$. This may be attributed due to the particles tend to minimize their surface free energy by growing into larger particles. These results are consistent with the conclusion drawn from XRD measurements.

Figure 3 shows the FTIR spectra of STO samples annealed at different temperatures. It has been reported that the IR bands of solids are usually assigned to vibration of ions in the crystal lattice. All FTIR spectra of STO show the absorption band at $400-750 \mathrm{~cm}^{-1}$, corresponding to the $\mathrm{TiO}_{6}$ octahedron in the crystal, which reveals that the STO crystal structure started forming at 600 ${ }^{\circ} \mathrm{C}$. However, the intensity of absorption peak significantly increased as temperature increased to above $900^{\circ} \mathrm{C}$. It is consistent with the result that was reported by M. Muralidharan group [10]. The XRD and FTIR results suggests that STO materials could be prepared by the sol-gel method and the optimized annealing temperature for the best quality of crystalline is in a range from $800^{\circ} \mathrm{C}$ to $1000^{\circ} \mathrm{C}$.

The Raman spectra of STO particles annealed at different temperatures are shown in Fig. 4. The results show that some peaks with very weak intensity started appearing as the sample 

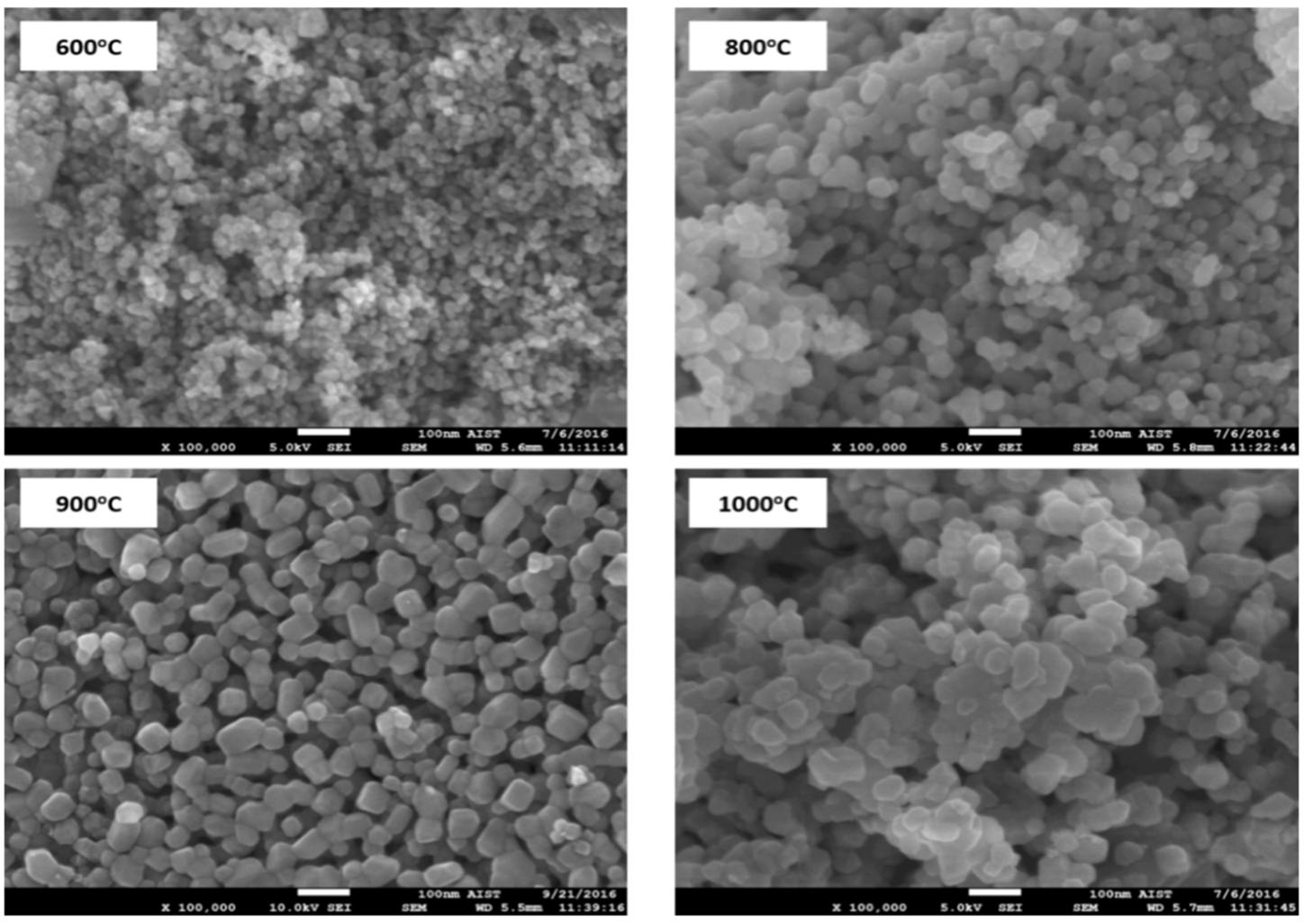

Fig. 2. SEM images of STO samples calcined at $600^{\circ} \mathrm{C}, 800^{\circ} \mathrm{C}, 900^{\circ} \mathrm{C}, 1000^{\circ} \mathrm{C}$.

was annealed at $600^{\circ} \mathrm{C}$. However, the Raman bands are shaper and well defined as the calcination temperature increased to $900^{\circ} \mathrm{C}$ and $1000^{\circ} \mathrm{C}$. There are four phonon bands were found in Raman spectra. The $\mathrm{E}_{g}$ mode at $\sim 145 \mathrm{~cm}^{-1}$ and $\mathrm{TO}_{2}-\mathrm{LO}_{1}$ band at $175 \mathrm{~cm}^{-1}$ were assigned to the resistance of $\mathrm{Sr}$ ion to the movement of $\mathrm{TiO}_{6}$ octahedron. The $\mathrm{TO}_{4}$ mode at $545 \mathrm{~cm}^{-1}$ related to stretching osciallation of Ti-O bond and band $\mathrm{LO}_{4}-\mathrm{A}_{2 g}$ at $795 \mathrm{~cm}^{-1}$ showed the expansion due to changes in components arising from random distribution of Ti cations in STO crystal lattice. This result was in agreement with the previously published one [14]. Similar to the XRD data and FTIR spectra, the Raman modes reaffirmed that STO samples were well crystallized in a range $800^{\circ} \mathrm{C}-$ $1000^{\circ} \mathrm{C}$.

The dependence of the absorption spectra of STO samples on annealing temperatures are shown in Fig. 5a. All samples present a well-defined absorption in ultraviolet (UV) region. As SrTiO3 is an indirect gap semiconductor [15] and thus the optical band gap (Eg) of the prepared SrTiO3 can be estimated from the tangent lines in the plots of the square root of the Kubelka-Munk functions against the photon energy, as shown in figure 5b [16], using Wood and Tauc estimating method [17]. The value of Eg is in the range $3.04 \mathrm{eV}$ to $3.18 \mathrm{eV}$. This result is fairly consistent with the result that was announced by M. Muralidharan et al. [10]. The band gap of prepared STO 
particles is very close to that of some photocatalytic materials such as $\mathrm{TiO} 2$. Therefore, it could be used for photocatalytic applications by doping or producing composite materials.

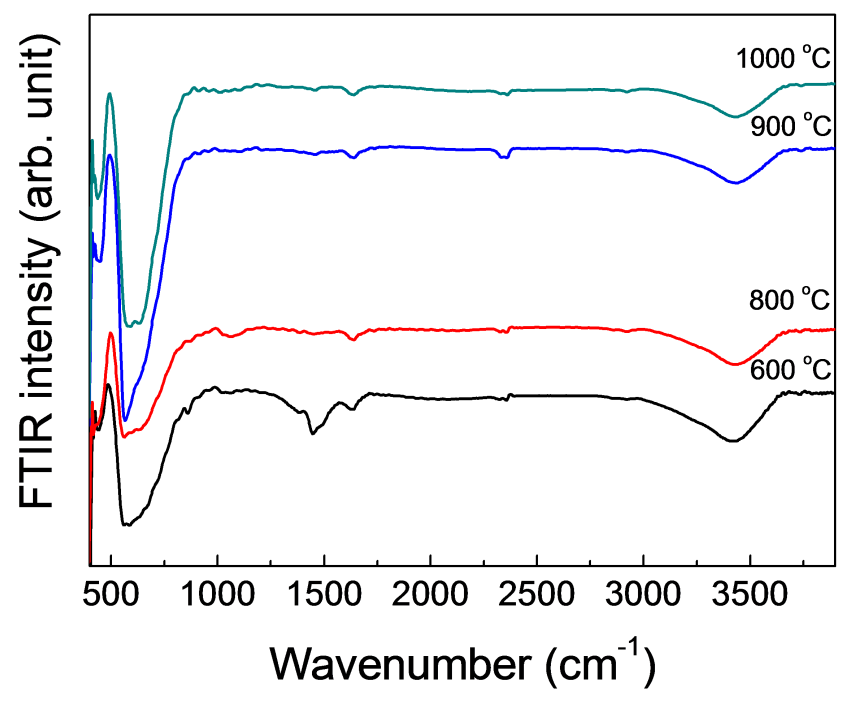

Fig. 3. FTIR spectrum of STO samples at different temperatures.

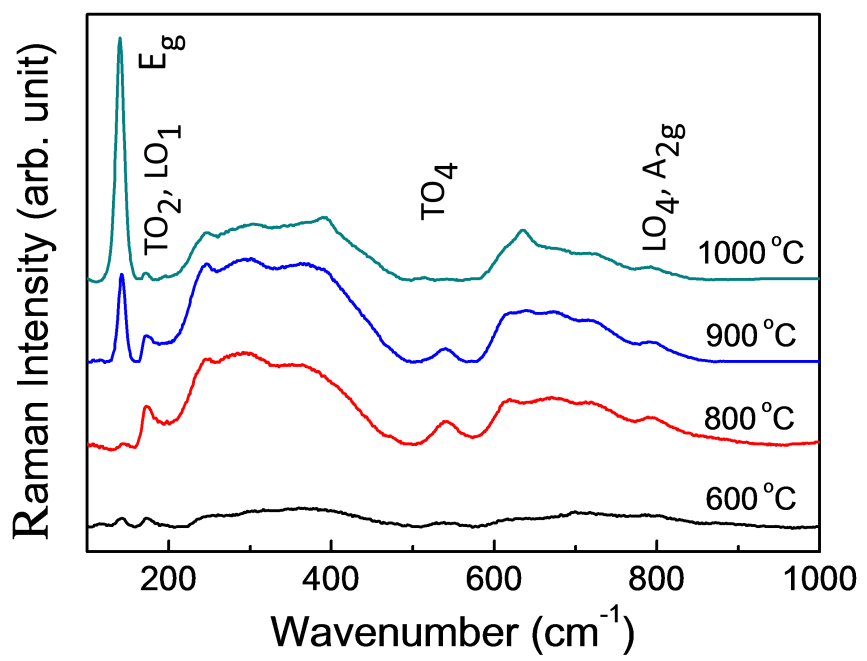

Fig. 4. Raman scattering spectroscopy of STO samples calcined at different temperatures. 

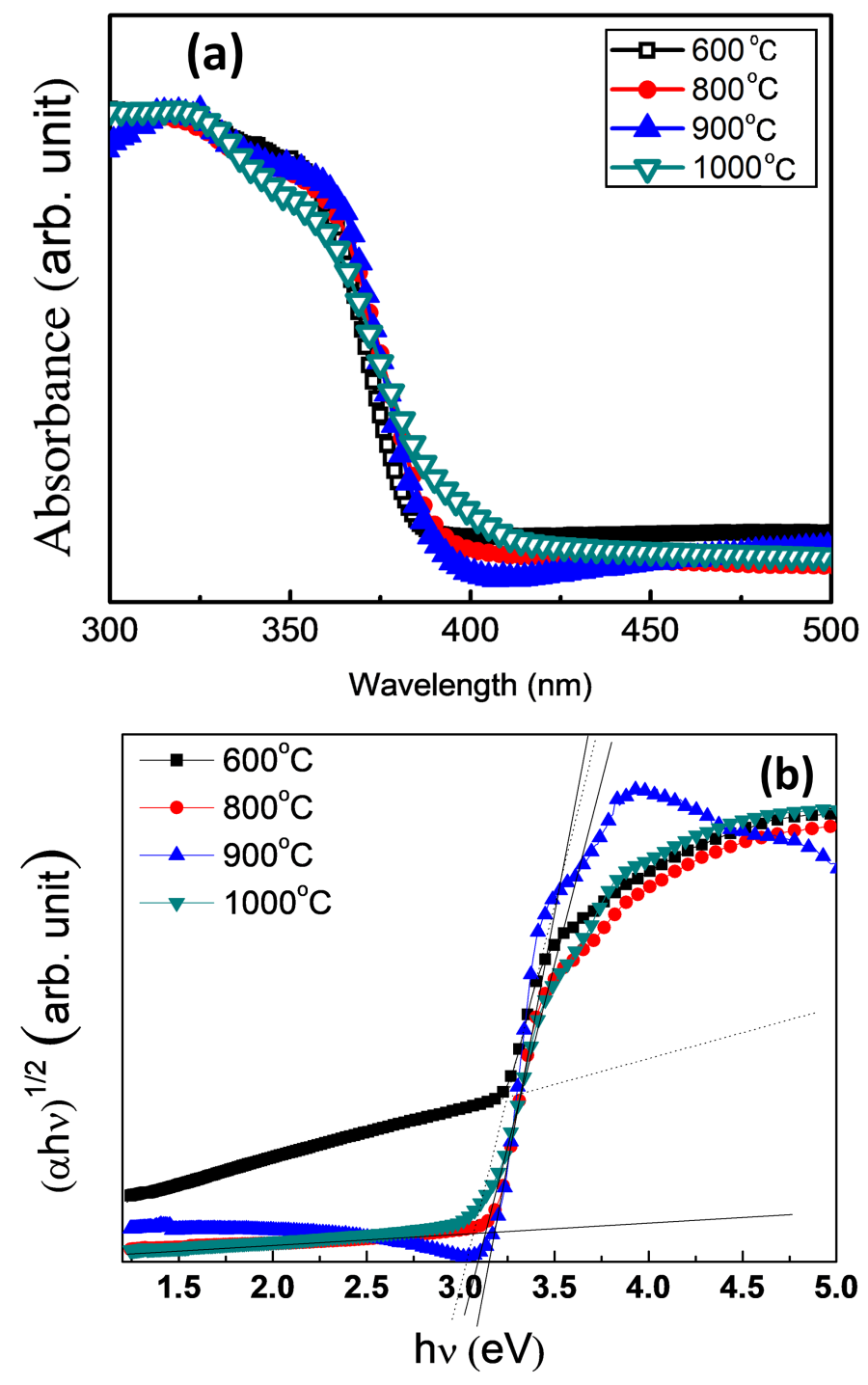

Fig. 5. Absorption spectra (a) and the plots of the square root of the Kubelka-Munk function against photon (b) of STO samples calcined at different temperatures.

\section{CONCLUSION}

In summary, on the basis of the XRD, SEM, FTIR and Raman analyses, the $\mathrm{SrTiO}_{3}$ nano particles have been successfully synthesized by the sol-gel method. The effect of annealing temperature on the structural and optical properties was studied. The optimization temperature for preparing STO nano particles is in range from $900^{\circ} \mathrm{C}$ to $1000^{\circ} \mathrm{C}$. The prepared STO particles, with spherical like shape and the optical band gap of 3.04-3.18 eV, could be used for further purposes such as combinating with other materials to make composites for photocatlytic applications. 


\section{ACKNOWLEDGEMENT}

This research is supported by science research topic T2017 - KHCB - 64, University of Transport and Communications

\section{REFERENCES}

[1] S. K. Kwon, J. H. Park and B. I. Min, Phys. Rev. B 62 (2000) R14637.

[2] S. G. Cho and P. F. Johnson, J. Mater. Sci. 29 (18) (1994) 4866.

[3] J. W. Liu, G. Chen, Z. H. Li and Z. G. Zhang, Journal of Solid State Chemistry 179 (2006) 3704.

[4] J. Daniels and K. H. Hardtl, Phillips Res. Repts. 31 (1976) 489.

[5] J. Fleig, S. Rodewald and J. Maier, J. Appl. Phys. 87 (2000) 2372.

[6] C. H. Perry, J. H. Fertel and T. F. McNelly, J. Chem. Phys. 47 (5) (1967) 1619.

[7] S. Malo, A. Maignan, Inorg. Chem. 43 (25) (2004) 8169.

[8] S. Rodewald, J. Fleig, J. Maier, J. Am. Ceram. Soc. 84 (2001) 521.

[9] L. F. D. Silva, M. I. B. Bernardi, L. J. Q. Maia, G. J. M. Frigo, V. R. Mastelaro, J. Therm. Anal. Calorim. 97 (1) (2009) 173.

[10] M. Muralidharan, V. Anbarasu, A. Elaya Perumal, K. Sivakumar, J Mater Sci: Mater Electron 26 (9) (2015) 6352.

[11] H. Bai, Z. Liu, D. D. Sun, J. Am. Ceram. Soc. 96 (3) (2013) 942.

[12] T. Cao, Y. Li, C. Wang, C. Shao, Y. Liu, Langmuir 27 (2011) 2946.

[13] J. Han, F. Wan, Z. Zhu, W. Zhang, Appl. Phys. Lett. 90 (2007) 031104.

[14] J. Petzelt, T. Ostapchuk, I. Gregora, I. Rychetsky, S. Hoffmann-Eifert, A. V. Pronin, Y. Yuzyuk, B. P. Gorshunov, S. Kamba, V. Bovtun, J. Pokorny, M. Savinov, V. Porokhonskyy, D. Rafaja, P. Vanek, A. Almeida, M. R. Chaves, A. A. Volkov, M. Dressel, R. Waser, Phys. Rev. B 64 (2001) 184111.

[15] F. P. Koffyberg, K. Dwight, A. Wold, Solid State Commun. 30 (7) (1979) 433.

[16] Y. I. Kim, S. J. Atherton, E. S. Brigham, T. E. Mallouk, Phys. Chem. 97 (1993) 11802.

[17] D. L. Wood and J. Tauc, Phy. Rev. B 5 (8) (1972) 3144. 